\title{
Relative vitamin A values of 9-cis- and 13-cis- $\beta$-carotene do not differ when fed at physiological levels during vitamin $A$ depletion in Mongolian gerbils (Meriones unguiculatus)
}

\author{
Kara A. Bresnahan, Christopher R. Davis and Sherry A. Tanumihardjo* \\ Interdepartmental Graduate Program in Nutritional Sciences, University of Wisconsin-Madison, \\ 1415 Linden Drive, Madison, WI 53706, USA \\ (Submitted 4 November 2013 - Final revision received 28 January 2014-Accepted 11 February 2014 - First published online 8 April 2014)
}

\begin{abstract}
Provitamin A biofortification of staple crops may decrease the prevalence of vitamin A (VA) deficiency if widely adopted in target countries. To assess the impact of processing methods on the VA value of plant foods, the unique bioefficacies of $c i s-\beta C$ isomers (formed during cooking) compared with all-trans (at) $\beta$-carotene $(\beta C)$ must be determined. The bioefficacies of 9 -cis $(9 c)$ - and 13 -cis (13c)- $\beta C$ isomers were compared with those of the at- $\beta \mathrm{C}$ isomer and VA positive $(\mathrm{VA}+)$ and negative $(\mathrm{VA}-$ ) controls in VA-depleted Mongolian gerbils (Meriones unguiculatus) in two experimental studies (study $1, n 56$; study 2, n 57). A 3- or 4-week depletion period was followed by a 3- or 4-week treatment period in which the groups received oral doses of the $9 c$-, $13 c$ - or at- $\beta C$ isomers in cottonseed oil (study $1,15 \mathrm{nmol} / \mathrm{d} ;$ study $2,30 \mathrm{nmol} / \mathrm{d}$ ). In study 1 , the $\beta C$ isomers did not maintain baseline liver VA stores in all groups ( 0.69 (SD 0.20$) \mu m o l /$ liver) except in the VA+group (0.56 (SD $0 \cdot 10) \mu \mathrm{mol} /$ liver $(P=0 \cdot 0026)$. The $\beta \mathrm{C}$ groups were similar to the VA+group, but the $9 c$ - and $13 c-\beta C$ groups did not differ from the VA-group (0.39 (SD 0.09) $\mu \mathrm{mol} /$ liver). In study 2 , the $\beta C$ isomers maintained baseline liver VA stores in all the $\beta C$ groups $(0.35$ (SD 0.13$) \mu \mathrm{mol} /$ liver), and in the VA+group, the VA supplement (0.54 (SD 0.19) $\mu \mathrm{mol} /$ liver) exceeded the baseline VA status (0.38 (SD 0.15) $\mu \mathrm{mol} /$ liver) $(P<0 \cdot 0001)$; however, the $9 c-\beta C$ group did not differ from the VA- group ( $0 \cdot 20$ (sD 0.07) $\mu \mathrm{mol} /$ liver). In vivo isomerisation of $\beta C$ was confirmed in both experimental studies. Lower VA bioconversion factor values were obtained for the $c i s-\beta C$ isomers in study 2 when compared with study 1 , but higher values were obtained for the at- $\beta C$ isomer. Dose and VA status clearly affect bioconversion factors. In conclusion, the $c i s-\beta C$ isomers yielded similar liver VA stores to the at- $\beta C$ isomer in Mongolian gerbils, and liver VA stores of the $9 c$ - and $13 c-\beta C$ groups did not differ when the doses were provided at physiological levels over time in two studies.
\end{abstract}

Key words: $\beta$-Carotene: Bioavailability: Bioconversion: Isomer effects

$\beta$-Carotene ( $\beta C$ ) is one of the most common carotenoids in the human diet ${ }^{(1)}$, and its primary function in the body is provitamin A activity ${ }^{(2)}$. All-trans (at)- $\beta C$ is the most abundant isomer in fresh plant foods, but thermal processing can increase the proportion of 9 -cis $(9 c)$ - and 13-cis (13c)- $\beta$ C isomers up to $50 \%{ }^{(3)}$. Little is known about the vitamin A (VA) efficacies of the $c i s-\beta C$ isomers, which have been collectively assigned a bioavailability equivalent to half that of at $-\beta C^{(4)}$. Therefore, it is imperative to determine the unique bioefficacies of the cis- $\beta C$ isomers to better understand the impact of thermal processing methods on the VA value of plant foods.

VA deficiency is a global health concern, affecting 190 million children under 5 years of age ${ }^{(5)}$. The introduction of provitamin A carotenoid-biofortified staple crops is a novel approach to alleviate VA deficiency and prevent issues observed with preformed VA supplementation and fortification, such as cyclical liver stores and hypervitaminosis risk ${ }^{(6)}$. However, staple crops undergo thermal processing before consumption; thus, the impact of isomerisation may need to be considered when establishing biofortification targets in order to ensure adequate delivery of VA to target populations.

A study by Deming et al. ${ }^{(7)}$ has determined the individual bioavailabilities of $9 c$ - and $13 c-\beta C$ isomers in gerbils to be 38 and $62 \%$ that of at- $\beta C$, respectively, using doses that ranged between 141 and $418 \mathrm{nmol} \beta \mathrm{C} / \mathrm{d}$ or 132 and $392 \mathrm{nmol} \mathrm{VA} / \mathrm{d}$ according to the Institute of Medicine (IOM)'s recommended values of $2 \mu \mathrm{g}$ at- $\beta \mathrm{C}$ to $1 \mu \mathrm{g}$ retinol activity equivalents for supplemental $\beta C^{(4)}$. These orally administered doses greatly exceeded the utilisation rate $(10 \cdot 8 \mathrm{nmol} \mathrm{VA} / 100 \mathrm{~g}$ body weight $/ \mathrm{d}^{(8)}$ ) and the current recommendation of the

Abbreviations: at, all-trans; $\beta \mathrm{C}, \beta$-carotene; $9 c$, 9-cis; $13 c, 13$-cis; IOM, Institute of Medicine; VA, vitamin A; VA+, retinyl acetate in cottonseed oil; $\mathrm{VA}-$, vitamin A-free cottonseed oil. 
National Research Council for a typical adult gerbil $(15 \cdot 1 \mathrm{nmol}$ $\mathrm{VA} / \mathrm{d}$, assuming an average feed intake of approximately $\left.6 \mathrm{~g}^{(9)}\right)$, and therefore they are not reflective of typical dietary intake that would be achieved from staple crops. Howe et $a{ }^{(10)}$ found that $\beta \mathrm{C}$-enhanced cassava feeds providing $10 \cdot 9-27.5 \mathrm{nmol} \beta \mathrm{C} / \mathrm{d}$ maintained VA status in gerbils despite $40-50 \%$ cis- $\beta \mathrm{C}$ isomer content in cassava. Additionally, in an in vitro study using isomeric mixtures, the $9 c-\beta C$ isomer enhanced overall total carotene in solution and resulted in constant or enhanced micellar incorporation ${ }^{(11)}$. Thus, the objective of the present study was to compare the bioefficacies of the $9 c-, 13 c$ - and at- $\beta C$ isomers in VA-depleted gerbils using doses reflective of dietary intakes from staple foods. Conversion to retinol was determined using total liver VA stores compared with a positive preformed retinol-supplemented group and a negative VA-depleted group.

\section{Materials and methods \\ Chemicals and dose preparation}

Crystalline at- $\beta C$ (Sigma-Aldrich), $9 c-\beta C$ and $13 c-\beta C$ (gifts from Hoffmann-La Roche, Inc.) were prepared for purification by dissolution in $n$-hexane. $\beta C$ isomers were purified on an open column using $\mathrm{Al}$ as the stationary phase and $n$-hexane as the mobile phase. The purities of all $\beta C$ isomers were confirmed as $>99 \%$ with HPLC. For stock solutions, purified $\beta C$ in hexane was condensed to $10 \mathrm{ml}$ under $\mathrm{N}_{2}$, mixed with $20 \mathrm{ml}$ cottonseed oil in an amber vial, and dried to remove remaining hexane and ensure clear solutions. The removal of hexane was confirmed by repeated weighing until a constant weight was achieved. Using spectrophotometry, concentrations were calculated with $E_{1 \%}^{1 \%}=2590$ for the at- $\beta \mathrm{C}$ isomer at $450 \mathrm{~nm}, E_{1 \mathrm{~cm}}^{1 \%}=2550$ for the $9 c-\beta C$ isomer at $445 \mathrm{~nm}$ and $E_{1 \mathrm{~cm}}^{1 \%}=2090$ for the $13 c-\beta C$ isomer at $443 \mathrm{~nm}^{(12)}$. Specific volumes of stock solution were pipetted into amber vials containing the appropriate amount of oil to achieve the target dose and were mixed by sonication; final doses were validated by dissolution of the dose in hexane followed by spectrophotometry where the reference cell contained an equal amount of oil dissolved in hexane. Doses were divided and stored at $-70^{\circ} \mathrm{C}$ to minimise isomerisation. Lack of isomerisation during dose preparation was confirmed by running an aliquot of the oil dose dissolved in isopropanol on the HPLC system. A new bottle was opened at each study week.

\section{Study design}

Male Mongolian gerbils (Meriones unguiculatus) (study 1, $n$ 56; study 2, $n$ 57; Charles River Laboratories), aged $34 \mathrm{~d}$ old, were group-housed ( $n$ 2-3 per cage) throughout the study. Room temperature and humidity were held constant (12 h light-dark cycle). Gerbils were acclimatised to the dosing procedure before the start of the treatments by orally administering $40 \mu \mathrm{l}$ cottonseed oil/d using a positive displacement pipette. Gerbils were weighed on a daily basis for about 2 weeks and thereafter were weighed twice per week. Animal handling procedures were approved by the College of
Agriculture and Life Sciences Animal Care and Use Committee at University of Wisconsin-Madison.

Gerbils consumed ad libitum water and VA- and carotenoidfree, semi-purified, powdered feed for the duration of the study. The feed was designed in consultation with a feed nutritionist (Harlan-Teklad) to meet the gerbils' energy and nutrient requirements without any known source of VA or $\beta C$ (Table 1). Feed intake was determined by measuring the feed in a clean bowl and subtracting the remainder after a $24 \mathrm{~h}$ period. After depletion (study 1, 3 weeks; study 2, 4 weeks), a baseline group (study $1, n 6$; study $2, n 7$ ) was killed via exsanguination while under isoflurane anaesthesia to determine initial serum and liver VA concentrations. The remaining cages were sorted into weight-matched treatment groups ( $n 10$ per group). To ensure $90 \%$ power with a $5 \%$ significance level, nine gerbils per treatment group were necessary to detect a $30 \mathrm{nmol}$ difference in liver retinol concentration, assuming a standard deviation of $20 \mathrm{nmol}$. The sample size was increased to ten gerbils per group to account for the animals that may fail to thrive during the experimental period or to mitigate outliers.

In the present study, three groups received daily oral doses of at-, $9 c$ - or $13 c-\beta C$ in cottonseed oil, and the other groups received doses of VA-free cottonseed oil (VA-) or retinyl acetate in cottonseed oil (VA+). In study 1 , a low $\beta C$ dose of $15 \mathrm{nmol} / \mathrm{d}$ was designed to provide twice the molar equivalent of the daily VA utilisation rate of a $70 \mathrm{~g}$ gerbil $^{(8)}$. In study 2 , a moderate $\beta C$ dose of $30 \mathrm{nmol} / \mathrm{d}$ was designed to provide twice the molar equivalent of the current VA recommendation of $2.5 \mathrm{nmol} / \mathrm{g}$ feed $^{(9)}$, assuming a typical feed intake of approximately $6 \mathrm{~g} / \mathrm{d}$. The retinyl acetate dose provided the proportion of $1 \mu \mathrm{g}$ retinol: $2 \mu \mathrm{g}$ at $\beta \mathrm{C}$ in accordance with the current equivalents of the IOM for oil $\beta C$ supplements ${ }^{(4)}$ Following a 3-week (study 1) or a 4-week (study 2) treatment period, gerbils were killed. Blood was allowed to clot at room temperature for $30 \mathrm{~min}$ and centrifuged for $15 \mathrm{~min}$ at $2200 \mathrm{~g}$ at $4^{\circ} \mathrm{C}$ in vacutainer tubes (Becton Dickinson). Serum and liver samples were stored at $-70^{\circ} \mathrm{C}$.

Table 1. Composition of a vitamin A (VA)- and carotenoid-free gerbil feed

\begin{tabular}{lc}
\hline Ingredients & VA- and carotenoid-free feed $(\mathrm{g} / \mathrm{kg})$ \\
\hline Casein, vitamin-free & 200 \\
L-Cys & $3 \cdot 0$ \\
Sucrose & $360 \cdot 5$ \\
Maltodextrin & 120 \\
Maize starch & 150 \\
Cottonseed oil & 60 \\
Cellulose & 60 \\
Mineral mix, AIN-93M-MX & 35 \\
Magnesium oxide & $1 \cdot 75$ \\
Calcium phosphate, dibasic & $2 \cdot 0$ \\
Vitamin mix & $5 \cdot 0$ \\
Vitamin E acetate & $0 \cdot 242$ \\
Vitamin $\mathrm{D}_{3}$ & $0 \cdot 004$ \\
Choline bitartrate & $2 \cdot 5$ \\
\end{tabular}

* Provided per $\mathrm{kg}$ of purified diet: biotin, $0.4 \mathrm{mg}$; calcium pantothenate, $66.1 \mathrm{mg}$; folic acid, $2 \mathrm{mg}$; inositol, $110.1 \mathrm{mg}$; menadione, $49.6 \mathrm{mg}$; niacin, $99.1 \mathrm{mg}$; p-aminobenzoic acid, $110.1 \mathrm{mg}$; pyridoxine- $\mathrm{HCl}, 22 \mathrm{mg}$; riboflavin, $22 \mathrm{mg}$; thiamin- $\mathrm{HCl}, 22 \mathrm{mg}$; vitamin $\mathrm{B}_{12}(0.1 \%$ in mannitol $), 29.7 \mathrm{mg}$; ascorbic acid (97.5\%), 1016.6 mg. 


\section{Tissue extraction procedures}

Samples were analysed under gold light to prevent photooxidation and isomerisation. C-23 apo-carotenol was used as the internal standard in all serum and liver samples. A modified procedure was used for the analysis of serum ${ }^{(13)}$. In study 1 , $500 \mu \mathrm{l}$ serum was analysed, reconstituted in $100 \mu \mathrm{l}$ of methanol-dichloroethane (50:50), and $25 \mu \mathrm{l}$ injected. In study 2 , to assess the isomeric profile, $1000 \mu \mathrm{l}$ serum was analysed, reconstituted in $80 \mu \mathrm{l}$ of methanol-butanol (70:30), and $50 \mu$ injected.

Liver (approximately $0.7 \mathrm{~g}$ ) was ground with approximately $4 \mathrm{~g}$ sodium sulphate, extracted with dichloromethane, filtered and made up to $50 \mathrm{ml}$. For retinoid and carotenoid analyses, aliquots of 5 and $15 \mathrm{ml}$, respectively, were dried under $\mathrm{N}_{2}$, reconstituted in $100 \mu \mathrm{l}$ of methanol-dichloroethane (50:50), and 25 or $50 \mu$ injected.

\section{HPLC analyses}

$\beta C$ isomers were separated from the oil doses and liver samples using a C30 YMC carotenoid column $(4.6 \times 250 \mathrm{~mm}$, $3 \mu \mathrm{m}$; Waters, Inc.) at $450 \mathrm{~nm}$, as described previously ${ }^{(14)}$, on a Waters HPLC system consisting of a 1525 binary HPLC pump, a 717 autosampler and a 996 photodiode array detector. The samples were held at $4^{\circ} \mathrm{C}$ in the autosampler to prevent isomerisation or degradation.

For serum analysis in study 1 and all liver analyses, retinol and retinyl esters were separated using a Resolve C18 column $(3.9 \times 300 \mathrm{~mm}, 5 \mu \mathrm{m}$; Waters, Inc.) at $325 \mathrm{~nm}$. Solvent A was acetonitrile-water (85:15) with $10 \mathrm{~mm}$-ammonium acetate and solvent $\mathrm{B}$ was acetonitrile-methanol-dichloroethane (85:10:5) with $10 \mathrm{~mm}$-ammonium acetate. Gradient elution was performed at $2 \mathrm{ml} / \mathrm{min}$ using the following procedure: $100 \% \mathrm{~A}$ for $3 \mathrm{~min}, 7 \mathrm{~min}$ linear gradient to $100 \% \mathrm{~B}, 15 \mathrm{~min}$ hold and $2 \mathrm{~min}$ reverse gradient to $100 \% \mathrm{~A}$. Identities of $\beta C$ isomers, retinol and retinyl esters were determined using HPLC-purified standards. Total liver VA stores were calculated by summing retinol and identifiable retinyl esters. For serum analysis in study 2 , retinol isomers were separated using a Zorbax ODS C18 column $(4.6 \times 250 \mathrm{~mm}, 5 \mu \mathrm{m}$; Dupont $)$ at $325 \mathrm{~nm}$ with an isocratic mobile phase of methanol-waterbutanol (50:27:23) with $10 \mathrm{mm-ammonium} \mathrm{acetate} \mathrm{run} \mathrm{at}$ $1 \mathrm{ml} / \mathrm{min}$. Identities of the retinol isomers were confirmed using the elution order determined by MacCrehan \& Schönberger ${ }^{(15)}$ and HPLC spectra. All tissue samples were run on a Waters HPLC system consisting of a Delta 600 quaternary HPLC pump, a 600 controller and a 2487 dual absorbance detector, and the samples were injected manually. C-23 alcohol was used as the internal standard, and standard curves were constructed for the quantification of carotenoids and retinoids.

\section{Statistical analysis}

Results are presented as means and standard deviations. Data were analysed using SAS software (version 8.2; SAS Institute). Outcomes of interest (gerbil body and liver weights, serum retinol, and liver retinol and carotenoids) were evaluated using a one-way ANOVA. Differences between groups were determined using the least significant difference test at $\alpha<0.05$. An arcsine-square-root transformation was used to homogenise variance expressed as percentages. Bioconversion factors of $\beta C$ to retinol were calculated using differences in total liver VA in the $\beta \mathrm{C}$-treated groups compared directly with the VA+group after correction for the VA- group.

\section{Results}

\section{Gerbil weights}

In study 1 , the final gerbil weights did not differ between the experimental groups $(77.7$ (SD 5.15) g) but were found to be higher than that of the baseline group (67.4 (SD 6.62) g, $P=0.0043$ ). The final liver weights did not differ among the groups $(3.05$ (SD 0.42$) \mathrm{g}$ ). In study 2 , the final gerbil weights $(68.8$ (SD 5.63) g) and liver weights $(2.47$ (SD 0.35) g) were found to be similar among all the groups. Feed intakes did not differ within study 1 (6.42 (SD 1.07) g feed/d) or study 2 (5.05 (sD 0.69) $\mathrm{g} \mathrm{feed/d)} \mathrm{(Table} \mathrm{2).}$

\section{Serum retinol and carotenoids}

In both studies, total serum retinol concentration did not differ among the treatment groups, and carotenoids were not detected. In study 1 , the range of serum retinol concentrations was $1.43(\mathrm{SD} 0.12) \mu \mathrm{mol} / \mathrm{l}$ in the $13 c-\beta C$ group to 1.70 (SD 0.18 ) $\mu \mathrm{mol} / \mathrm{l}$ in the $\mathrm{VA}-$ group. In study 2 , the range was found to be $1.19(\mathrm{SD} 0 \cdot 12) \mu \mathrm{mol} / \mathrm{l}$ in the at $\beta$ C group to 1.27 (SD $0 \cdot 14$ ) $\mu \mathrm{mol} / \mathrm{l}$ in the baseline group, and the relative ratio of isomers varied across the treatment groups (Fig. 1). Serum retinol concentrations differed between studies 1 and 2 $(P<0 \cdot 0001)$. The composition of $9 c$-retinol in serum differed among the groups $(P=0.032)$. The proportion of $9 c$-retinol was similar among the $9 c-\beta C, 13 c-\beta C$, at $-\beta C$ and VA+ groups ( 1.94 (SD 0.50$) \%$ ), and the proportion for the baseline and VA-groups (1.59 (SD 0.19)\%) was found to be lower than that for the $13 c-\beta C$ and at- $\beta C$ groups (2.09 (SD 0.51$) \%$ ), but

Table 2. Gerbil feed consumption in two studies administering low $(15 \mathrm{nmol})$ and moderate $(30 \mathrm{nmol})$ doses of $\beta$-carotene $(\beta C)$ daily (Mean values and standard deviations)

\begin{tabular}{llll}
\hline & & \multicolumn{2}{c}{ Daily feed intake $(\mathrm{g} / \mathrm{d})$} \\
\cline { 3 - 4 } Treatment & $n$ & Mean & $\mathrm{SD}$ \\
\hline Low $\beta C$ intake & & & \\
$9 c-\beta C$ & 10 & 5.83 & 1.15 \\
$13 c-\beta C$ & 10 & 6.66 & 0.73 \\
at $-\beta C$ & 10 & 6.56 & 1.03 \\
VA + & 10 & 6.61 & 1.22 \\
VA - & 10 & 6.44 & 1.31 \\
Moderate $\beta C$ intake & & & \\
$9 c-\beta C$ & 10 & 4.93 & 0.92 \\
$13 c-\beta C$ & 10 & 5.08 & 0.53 \\
at $-\beta C$ & 10 & 4.86 & 0.86 \\
VA + & 10 & 4.93 & 0.25 \\
VA - & 10 & 5.53 & 1.16 \\
\hline
\end{tabular}

c, cis; at, all-trans; VA, vitamin A. 
Vitamin A values of $\beta$-carotene isomers

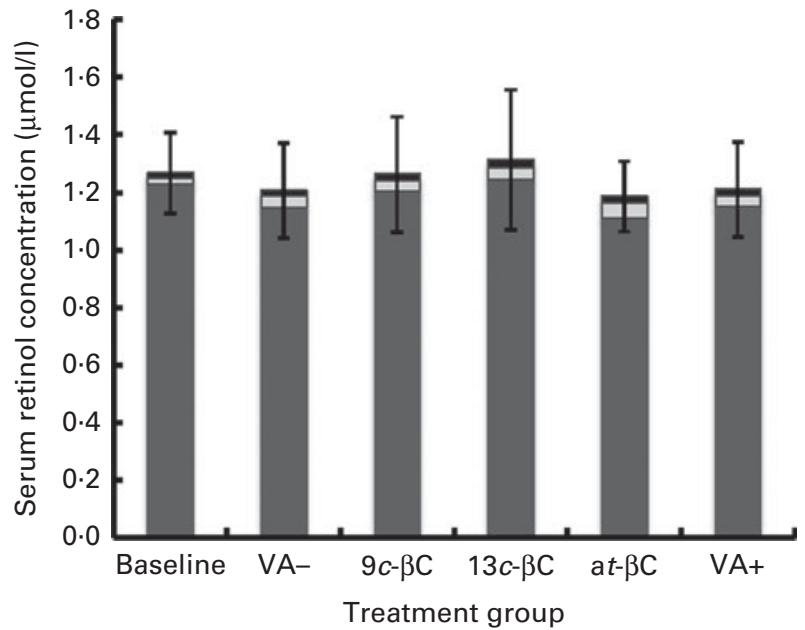

Fig. 1. Serum retinol concentrations in Mongolian gerbils (Meriones unguiculatus) fed a vitamin A (VA)- and carotenoid-free feed at baseline after 4 weeks (study 2) of depletion (baseline, $n 7$ ), or treated with VA-free cottonseed oil (VA-), moderate doses of $30 \mathrm{nmol}$ 9-cis-, 13-cis- or all-trans $\beta$-carotene $(9 c-\square, 13 c-\square$ or at $-\beta C \square$ ) in cottonseed oil, or retinyl acetate in cottonseed oil (VA+) for an additional 4 weeks. VA intake in the VA+ group was matched to one-half of the theoretical VA intake in the $\beta C$ groups. Values are means $(n 10)$, with standard deviations represented by vertical bars. The treatment groups did not differ significantly $(P>0.05$; ANOVA followed by least significant difference test).

did not differ from each other or the $9 c-\beta C$ and VA+ groups (1.77 (SD 0.46)\%). The composition of $13 c$-retinol did not differ among the groups (3.16 (SD 1.95)\%). The composition of at-retinol differed from baseline (96.7 (SD 0.50)\%, $P=0.021)$ in the $13 c-\beta C$ and at- $\beta C$ groups, but did not differ from each other $(94.1$ (SD 1.94)\%) or the VA-, $9 c-\beta C$ and $\mathrm{VA}+$ groups $(95 \cdot 1$ (SD 1.76)\%).

\section{Liver retinol and carotenoids}

In study 1 , concentrations of liver retinol did not differ among the experimental groups, and the $\beta C$ isomers did not maintain baseline liver stores in all the groups $(P=0.006$; Fig. 2(A)). Total liver retinol concentrations did not differ among the $\mathrm{VA}+, 9 c-\beta \mathrm{C}, 13 c-\beta \mathrm{C}$ and $\mathrm{at}-\beta \mathrm{C}$ groups, and the $\beta \mathrm{C}$ isomers failed to maintain baseline liver VA stores in all of these groups, except the VA+group $(P=0.0026$; Fig. 2(B)). The $9 c-$ and $13 c-\beta C$ groups did not differ from the VA-group. In study 2 , the $\beta C$ isomers maintained baseline liver retinol status in all groups, except the VA-group, which did not differ from the $9 c$ - and $13 c-\beta C$ groups $(P=0.0019$; Fig. 3(A)). Total liver retinol stores were found to be highest in the VA+ group and lowest in the VA-group $(P<0 \cdot 0001$; Fig. 3(B)). The VA- group did not differ from the $9 c-\beta C$ group, but all the $\beta C$ isomers resulted in similar total liver stores.

Carotenoids were not detected in the liver of the baseline, VA- and VA+groups in either study. In studies 1 and 2, total liver $\beta C$ concentration was found to be highest in the $9 c-\beta C$ group followed by the at $-\beta C$ and $13 c-\beta C$ groups (study 1, $P<0.0001$; study 2, $P<0.0001$; Table 3 ). The presence of the administered $\beta C$ isomer and the other two isomers in the liver demonstrated in vivo isomerisation of the $\beta C$ doses, and the relative proportions of the $\beta C$ isomers varied among these groups (Table 3 ).

\section{Bioconversion factors and utilisation rates}

Bioconversion factors for the $\beta \mathrm{C}$-treated groups were calculated by determining the total liver VA stores above the negative control and by directly comparing this value to that of the $\mathrm{VA}+$ group. Bioconversion factors ranged from 115 to $168 \%$ and 140 to $175 \%$ of the IOM's recommended values in studies 1 and 2 , respectively (Table 4). Comparison of the $9 c$ - and $13 c$ $\beta C$ isomers with the at $\beta C$ isomer resulted in mass equivalents of 2.9 and $1.6 \mu \mathrm{g} 9 c-\beta C$ and 2.6 and $1.4 \mu \mathrm{g} 13 c-\beta C$ to $1 \mu \mathrm{g}$ at$\beta C$ for studies 1 and 2 , respectively. In study 1 , the utilisation rate for the VA-group, which was deprived of VA for $21 \mathrm{~d}$ beyond baseline, was found to be $5 \cdot 1 \mu \mathrm{g} / 100 \mathrm{~g}$ body weight and for the VA+ group, which was supplemented cumulatively with $84.6 \mu \mathrm{g}$ retinol in the form of acetate, was $7.5 \mu \mathrm{g} / 100 \mathrm{~g}$ body weight. In study 2 , the utilisation rate for the VA-group, which was deprived of VA for an additional $14 \mathrm{~d}$ in the
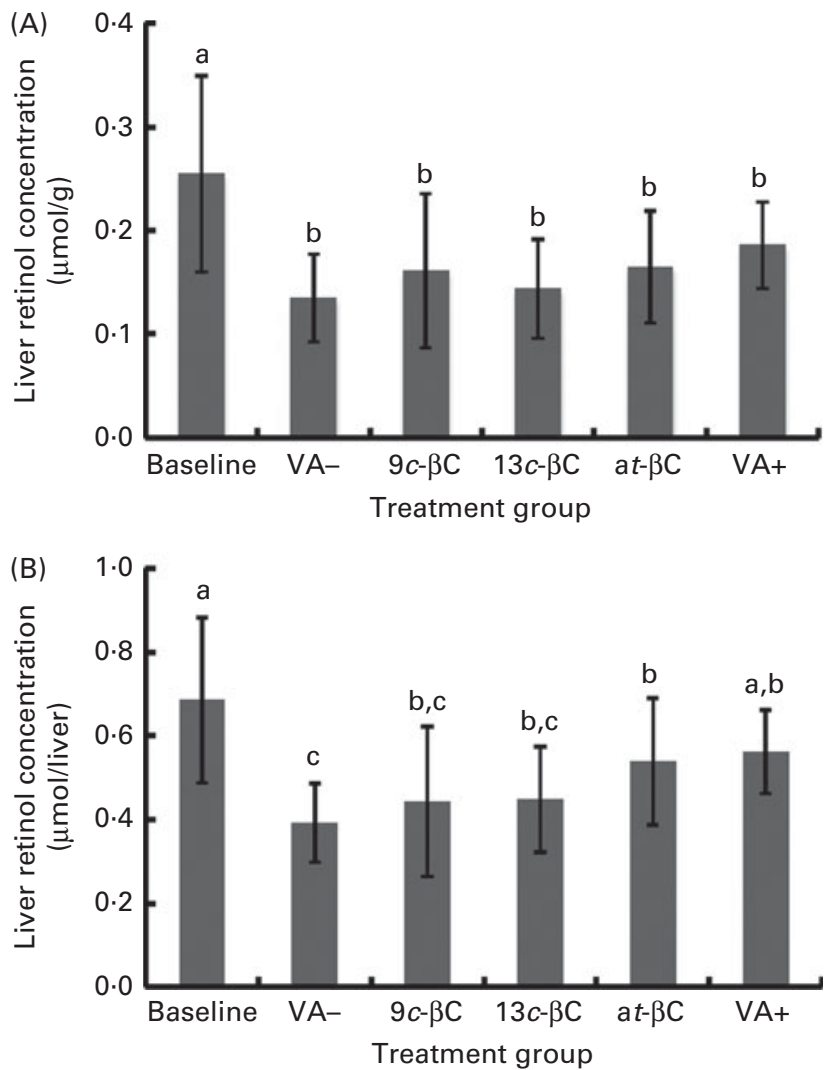

Fig. 2. Liver retinol $(A)$ and total liver retinol $(B)$ concentrations corrected for liver weight in Mongolian gerbils (Meriones unguiculatus) fed a vitamin A (VA)and carotenoid-free feed at baseline after 3 weeks (study 1) of depletion (baseline, $n$ 6), or treated with VA-free cottonseed oil (VA-), low doses of $15 \mathrm{nmol}$ 9-cis-, 13-cis- or all-trans $\beta$-carotene $(9 c-, 13 c$ - or at- $\beta C)$ in cottonseed oil, or retinyl acetate in cottonseed oil (VA+) for an additional 3 weeks. VA intake in the VA group was given at $1 \mu \mathrm{g}$ retinol equivalent to $2 \mu \mathrm{g} \beta \mathrm{C}$ provided to the $\beta C$ groups. Liver retinol was determined by pooling values for retinol and retinyl esters. Values are means ( $n 10)$, with standard deviations represented by vertical bars. ${ }^{a, b, c}$ Mean values with unlike letters were significantly different $(P<0.05 ;$ ANOVA followed by least significant difference test). 

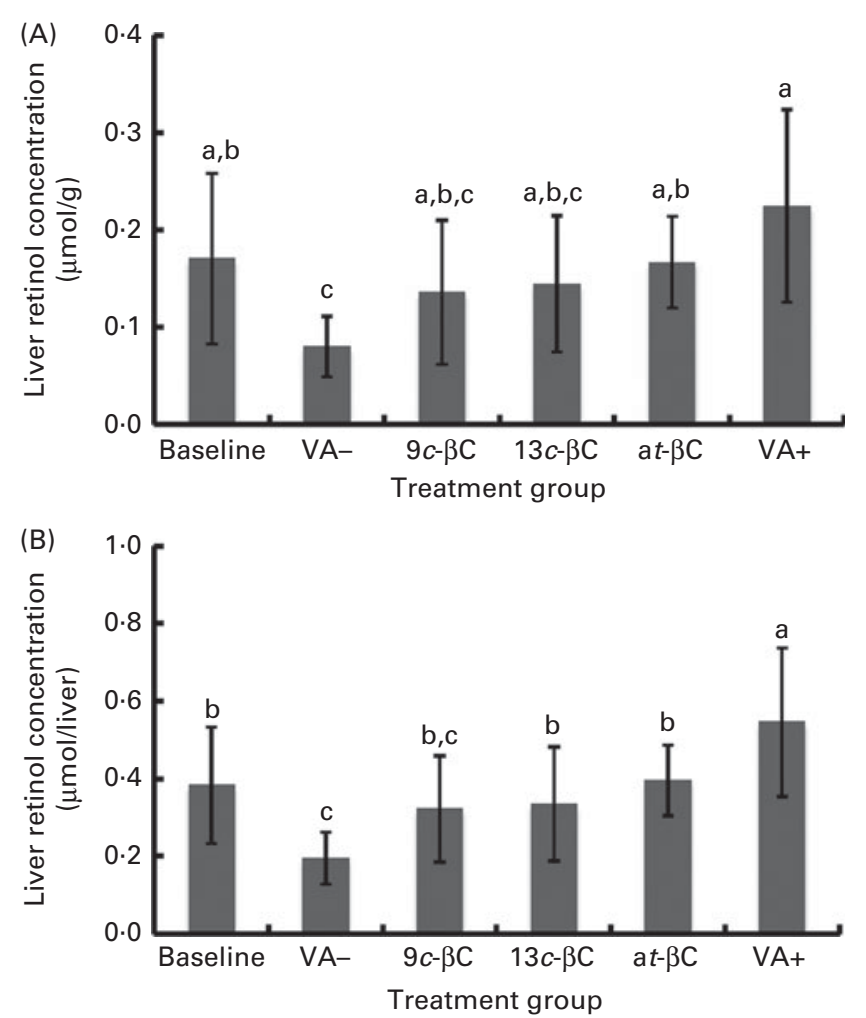

Fig. 3. Liver retinol (A) and total liver retinol (B) concentrations in Mongolian gerbils (Meriones unguiculatus) fed a vitamin A (VA)- and carotenoid-free feed at baseline after 4 weeks (study 2) of depletion (baseline, $n 7$ ), or treated with VA-free cottonseed oil (VA-), moderate doses of $30 \mathrm{nmol}$ 9-cis-, 13-cis- or all-trans $\beta$-carotene (9c-, 13c- or at- $\beta C$ ) in cottonseed oil, or retinyl acetate in cottonseed oil (VA+) for an additional 4 weeks. VA intake in the VA group was given at $1 \mu \mathrm{g}$ retinol equivalent to $2 \mu \mathrm{g} \beta \mathrm{C}$ provided to the $\beta C$ groups. Liver retinol was determined by pooling values for retinol and retinyl esters. Values are means $(n 10)$, with standard deviations represented by vertical bars. ${ }^{\mathrm{a}, \mathrm{b}, \mathrm{c}}$ Mean values with unlike letters were significantly different $(P<0.05$; ANOVA followed by least significant difference test).

extended depletion and treatment periods, was found to be $2 \cdot 7 \mu \mathrm{g} / 100 \mathrm{~g}$ body weight, and for the VA+group, which received a total of $225.7 \mu \mathrm{g}$ retinol, was $9 \cdot 1 \mu \mathrm{g} / 100 \mathrm{~g}$ body weight.

\section{Discussion}

To assess the impact of thermal processing methods on plant foods, it is essential to determine the unique VA bioefficacies of $c i s-\beta C$ isomers at physiological levels. To our knowledge, no other studies have investigated the bioefficacies of $\beta C$ isomers using amounts reflective of dietary intakes in animals with carotenoid metabolism similar to that of humans. In studies 1 and 2, the bioefficacies of $9 c-, 13 c$ - and at- $\beta \mathrm{C}$ in oil at low $(15 \mathrm{nmol})$ and moderate $(30 \mathrm{nmol})$ doses were compared directly with preformed VA supplements. In study 1 , the $\beta C$ isomers did not maintain liver retinol stores; however, in study 2 , at higher doses, all $\beta \mathrm{C}$ isomers maintained baseline liver stores and the VA supplement exceeded baseline VA status. Bioconversion factors were $15-75 \%$ less efficient than the current reference values of the IOM. Factors for the supplemental cis- $\beta C$ isomers were similar in each study, with midpoints of 6.4 and $5.3 \mu \mathrm{g}$ cis- $\beta \mathrm{C}: 1 \mu \mathrm{g}$ retinol, in studies 1 and 2 , respectively. Bioconversion factors for the supplemental at $\beta C$ isomer were found to be 2.3 and $3.5 \mu \mathrm{g}$ at- $\beta \mathrm{C}: 1 \mu \mathrm{g}$ retinol in both studies, which are similar to the reported values of $2 \cdot 5-4.6$ in previous gerbil studies ${ }^{(10,13,14,16)}$.

The utilisation rates within and between each study were not the same, but similar to those reported in previous gerbil studies $^{(8,16)}$. For the VA-group, the utilisation rate in study 2 was almost half of that in study 1, indicating that the gerbils were conserving and recycling more retinol during the period of prolonged deprivation. The higher utilisation of the VA+group in study 2 probably reflects the more concentrated preformed retinyl acetate dose that they received ${ }^{(17)}$. The $\beta C$ doses failed to maintain baseline liver VA stores in study 1, suggesting that the utilisation rates of gerbils exceeded the amount of bioavailable provitamin A provided. Lee et $a l .{ }^{(8)}$ determined the VA utilisation rate of a VA-deplete adult gerbil to be $3 \cdot 1 \mu \mathrm{g} / 100 \mathrm{~g}$ body weight. The difference in utilisation rates between study 1 (i.e. $5 \cdot 1 \mu \mathrm{g} / 100 \mathrm{~g}$ body weight) and Lee et $a l .{ }^{(8)}$ may be due to the gerbils having a higher requirement as they were $16-26 \mathrm{~d}$ younger, or due to the variation in the level of

Table 3. Total liver $\beta$-carotene $(\beta C)$ and isomeric compositions in Mongolian gerbils (Meriones unguiculatus) administered with low $(15 \mathrm{nmol})$ and moderate $(30 \mathrm{nmol})$ doses of 9 -cis-, $13-c i s-$ or all-trans $\beta C(9 c-, 13 c-\text { or at- } \beta C)^{*}$ (Mean values and standard deviations; $n 10$ per $\beta C$ group)

\begin{tabular}{|c|c|c|c|c|c|c|c|c|}
\hline & \multicolumn{2}{|c|}{$\begin{array}{l}\text { Total liver } \beta C \\
\quad(\mathrm{nmol})\end{array}$} & \multicolumn{2}{|c|}{$9 c-\beta C(\%)$} & \multicolumn{2}{|c|}{$13 c-\beta C(\%)$} & \multicolumn{2}{|c|}{ at $-\beta C(\%)$} \\
\hline & Mean & SD & Mean & SD & Mean & SD & Mean & SD \\
\hline \multicolumn{9}{|l|}{ Low $\beta C$ intake } \\
\hline $9 c-\beta C$ & $7 \cdot 3^{\mathrm{a}}$ & 1.3 & $68 \cdot 6^{\mathrm{a}}$ & 4.6 & $10 \cdot 2$ & 0.9 & $21 \cdot 3^{\mathrm{C}}$ & 3.8 \\
\hline $13 c-\beta C$ & $2 \cdot 4^{\mathrm{c}}$ & 0.46 & $39 \cdot 3^{b}$ & $5 \cdot 6$ & $12 \cdot 3$ & $4 \cdot 2$ & $48 \cdot 4^{b}$ & 4.4 \\
\hline$a t-\beta C$ & $4 \cdot 9^{\mathrm{b}}$ & $2 \cdot 0$ & $31 \cdot 2^{\mathrm{C}}$ & $13 \cdot 0$ & $12 \cdot 6$ & $2 \cdot 8$ & $56 \cdot 2^{\mathrm{a}}$ & $10 \cdot 7$ \\
\hline$P$ & \multicolumn{2}{|c|}{$<0.0001$} & \multicolumn{2}{|c|}{$<0.0001$} & \multicolumn{2}{|c|}{ NS } & \multicolumn{2}{|c|}{$<0.0001$} \\
\hline \multicolumn{9}{|l|}{ Moderate $\beta C$ intake } \\
\hline $9 c-\beta C$ & $5 \cdot 0^{\mathrm{a}}$ & 0.6 & $21.6^{\mathrm{C}}$ & $4 \cdot 1$ & $6 \cdot 2^{b}$ & $1 \cdot 2$ & $72 \cdot 2^{\mathrm{a}}$ & 3.4 \\
\hline $13 c-\beta C$ & $2 \cdot 2^{c}$ & 0.5 & $57 \cdot 1^{\mathrm{b}}$ & $6 \cdot 0$ & $9 \cdot 6^{\mathrm{a}}$ & 1.8 & $33 \cdot 2^{\mathrm{b}}$ & $6 \cdot 6$ \\
\hline at $-\beta C$ & $3 \cdot 2^{\mathrm{b}}$ & 0.5 & $69 \cdot 6^{a}$ & $3 \cdot 6$ & $9 \cdot 1^{\mathrm{a}}$ & 2.9 & $21 \cdot 3^{c}$ & $2 \cdot 3$ \\
\hline$P$ & \multicolumn{2}{|c|}{$<0.0001$} & \multicolumn{2}{|c|}{$<0.0001$} & \multicolumn{2}{|c|}{0.0029} & \multicolumn{2}{|c|}{$<0.0001$} \\
\hline
\end{tabular}

a,b,c Mean values within a column with unlike superscript letters were significantly different $(P<0.05)$.

* The limit of detection for $\beta C$ was $<0.007 \mathrm{nmol}$. 
Table 4. Bioconversion factors in Mongolian gerbils (Meriones unguiculatus) administered with low (15 nmol) or moderate ( $30 \mathrm{nmol})$ doses of $\beta$-carotene $(\beta C)^{*}$

\begin{tabular}{|c|c|c|c|c|c|}
\hline & $\begin{array}{l}\mu \mathrm{mol} \beta C \text { : } \\
1 \mu \mathrm{mol} \text { retinol }\end{array}$ & $\begin{array}{l}\mu \mathrm{g} \beta \mathrm{C}: \\
1 \mu \mathrm{g} \text { retinol }\end{array}$ & $\begin{array}{l}\text { IOM reference } \\
(\mu \mathrm{g} \beta \mathrm{C}: 1 \mu \mathrm{g} \text { retinol }) \dagger\end{array}$ & $\begin{array}{l}\text { Percentage of } \\
\text { IOM value }\end{array}$ & $\begin{array}{l}\text { Percentage of } \\
\text { at } \beta C \text { bioefficacy } \neq\end{array}$ \\
\hline \multicolumn{6}{|c|}{ Low $\beta C$ intake } \\
\hline $9 c-\beta C$ & $3 \cdot 6$ & $6 \cdot 7$ & 4.0 & 168 & 34 \\
\hline $13 c-\beta C$ & $3 \cdot 2$ & $6 \cdot 1$ & 4.0 & 153 & 37 \\
\hline$a t-\beta C$ & $1 \cdot 2$ & $2 \cdot 3$ & $2 \cdot 0$ & 115 & 100 \\
\hline \multicolumn{6}{|c|}{ Moderate $\beta C$ intake } \\
\hline $9 c-\beta C$ & 3.0 & $5 \cdot 6$ & 4.0 & 140 & 63 \\
\hline $13 c-\beta C$ & $2 \cdot 7$ & $5 \cdot 0$ & 4.0 & 125 & 70 \\
\hline$a t-\beta C$ & 1.9 & 3.5 & $2 \cdot 0$ & 175 & 100 \\
\hline
\end{tabular}

depletion ${ }^{(16,17)}$. In study 2 , the depletion period was extended to reach deficiency, which resulted in a similar utilisation rate (i.e. $2 \cdot 7 \mu \mathrm{g} / 100 \mathrm{~g}$ body weight) to that of the Lee et al.'s value, and doses were increased to allow for adequate VA storage in the $\beta C$-treated groups.

It is important to consider the impact of VA status on bioconversion factors. The utilisation rate slows and recycling becomes more efficient during the state of deficiency and the converse occurs when the status is sufficient ${ }^{(17,18)}$. This departure in utilisation rates between the VA-deplete and VA-replete groups can therefore lead to the inflation of conversion factors, which may partially explain the higher conversion factors in study 1 compared with study 2 for the cis- $\beta C$ isomers. The VA-group had higher VA status in study 1 than in study 2 where the depletion and treatment periods were extended. Furthermore, bioconversion of $\beta C$ to retinol in humans and gerbils is dependent on dose size $^{(19,20)}$ and is inversely related to VA status ${ }^{(21,22)}$, which may explain the difference in bioconversion factors for the at- $\beta C$ isomer between the two studies because the dose was doubled in study 2 .

In study 2 , the relative VA values of the $9 c$ - and $13 c-\beta C$ isomers were similar with bioefficacies of 63 and $70 \%$ that of the at- $\beta C$ isomer, respectively. In previous studies, the relative VA values of the $9 c$ - and $13 c-\beta C$ isomers compared with that of the at- $\beta C$ isomer were $33-61$ and $48-74 \%$, respectively, in rats ${ }^{(23-25)}$ and 38 and $62 \%$, respectively, in gerbils $^{(7)}$. The variations in the VA values determined in the previous studies may be due to the differences in the amount (0.6-224.4 $\mu \mathrm{g} \quad \beta \mathrm{C} / \mathrm{d})$ and duration (7-28d) of dosing, the depletion period (20-56 d) or the basis of calculation (i.e. body-weight gain $v$. liver $\mathrm{VA})^{(7,23-25)}$. The gerbil provides a more advantageous model for studying carotenoid metabolism compared with the rat because, like humans, they are capable of cleaving provitamin A carotenoids to retinal and absorbing physiological doses intact ${ }^{(8,26,27)}$. Although rats are efficient cleavers of $\beta C$ in the small intestine, they only absorb $\beta C$ intact under conditions of great dietary excess $^{(28-30)}$. The present study demonstrates more efficient conversion of the $c i s-\beta C$ isomers, particularly $9 c-\beta C$, in gerbils than that found by Deming et $a l .{ }^{(7)}$, which, again, is likely attributable to the larger dose size used in that study.
The observation of higher total liver $\beta C$ concentration found in the $9 c-\beta C$ group suggests that the $9 c-\beta C$ isomer may be more efficiently delivered to the liver. In vitro studies have suggested that the cis- $\beta \mathrm{C}$ isomers are similarly or more efficiently incorporated into micelles during digestion ${ }^{(11,31-33)}$, but data are inconsistent regarding the efficiency of $c i s-\beta C$ isomer uptake by intestinal cells ${ }^{(31-33)}$. Based on accumulation in human serum, the at- $\beta C$ isomer appears to be absorbed and/or packaged into the chylomicra more efficiently than the cis- $\beta \mathrm{C}$ isomers, with $13 c-\beta C$ being the predominant cis- $\beta C$ isomer ${ }^{(34-37)}$. Additionally, in human subjects fed supplements or Dunaliella bardawil containing an at- $\beta C: 9 c-\beta C$ ratio of approximately 50:50, the at- $\beta \mathrm{C}$ isomer appears to be preferentially incorporated into the chylomicra and VLDL ${ }^{(38-40)}$. However, in vivo interconversion of $\beta \mathrm{C}$ isomers, documented previously in human subjects ${ }^{(41)}$ and gerbils ${ }^{(37)}$ and confirmed in the present study, may have a positive impact on the VA values of the cis- $\beta \mathrm{C}$ isomers, and result in inaccurate interpretations of their bioavailabilities when confirmed solely by the presence of the isomer of interest. More work is necessary to elucidate common in vivo patterns for and mechanisms of $\beta \mathrm{C}$ isomer interconversion as none is apparent from the isomeric composition found in the gerbil liver in these studies. Furthermore, enzymatic isomerisation of $c i s-\beta C$ isomers to at-retinal by $\beta$-carotene $15,15^{\prime}$-mono-oxygenase 1 was observed in rats, with $9 c-\beta C$ converting to a mixture of $9 c-, 13 c$ - and at-retinal and $13 c$ - and at- $\beta C$ converting primarily to at-retinal ${ }^{(42)}$. In a previous study, the composition of retinol isomers in the liver of gerbils was determined to be similar among groups dosed with $\beta C$ isomers and the negative control, with cis- $\beta C$ isomers constituting approximately $10 \%$ of total liver VA ${ }^{(37)}$. Similarly, the isomeric composition of serum retinol in study 2 was found to be $3 \cdot 3-6 \cdot 5 \%$ of cis-retinol isomers, which supports the in vivo isomerisation of $\beta C$ and/or retinol. Together, these findings demonstrate that the isomeric compositions of liver and serum retinol do not reflect the dietary intake of $\beta C$, and that the at-retinol isomer appears to be preferable for the storage and circulation of VA.

The lack of the difference observed in liver VA stores among the $9 c-, 13 c$ - and at- $\beta \mathrm{C}$ groups and bioefficacies of the $c i s-\beta C$ isomers $>60 \%$ that of the at- $\beta C$ isomer contradicts the idea that the cis:trans ratio significantly decreases the VA value of 
plant foods. These findings support the conclusion made by Howe et al. ${ }^{(10)}$ that regular, moderate intakes of $c i s-\beta C$ isomers from plant foods allow for efficient absorption and bioconversion to VA in gerbils. The cassava feeds used by Howe et al. contained $41-47 \%$ of $c i s-\beta C$ isomers; by using a bioefficacy of $c i s-\beta C$ isomers equivalent to two-thirds that of the at $-\beta C$ isomer, the VA value may have been decreased by only $14-16 \%$. In fact, Howe et al. ${ }^{(10)}$ demonstrated a conversion factor of $3.7 \mu \mathrm{g}$ $\beta C: 1 \mu \mathrm{g}$ retinol, which is similar to the values from plant foods containing much lower concentrations of cis- $\beta \mathrm{C}$ isomers $^{(43,44)}$. Similar bioconversion factors for thermally processed provitamin A-biofortified cassava have recently been determined in women, ranging from $4 \cdot 2-4.5 \mu \mathrm{g} \beta \mathrm{C}: 1 \mu \mathrm{g}$ retinol depending on oil content ${ }^{(45)}$. Additionally, the matrix of certain plant foods can have a negative impact on the VA value ${ }^{(46)}$, in which case thermal processing can increase $\beta C$ bioavailability ${ }^{(33,47,48)}$. It is therefore important for nutritionists and plant breeders to holistically consider the impacts of processing on matrix effects and carotenoid concentrations when establishing provitamin A biofortification targets in staple crops.

Liver is the primary storage site of retinol in mammals and is considered the best measure of VA status ${ }^{(18)}$. Serum retinol concentrations do not provide an effective measure of status because of homeostatic regulation over a wide range of liver stores $^{(18)}$, as demonstrated by similar concentrations among all the treatment groups within both studies. In that regard, the difference between serum retinol concentrations between studies 1 and 2 is interesting, considering that the gerbils in study 2 received twice the supplemental doses and liver VA concentrations did not differ between the two studies. Subclinical deficiency has recently been defined as liver stores $<0 \cdot 1 \mu \mathrm{mol}$ retinol/g liver ${ }^{(18)}$; according to this definition, the VA- group in study 1 was nearing deficiency and the VA-group in study 2 was deficient, but serum retinol concentrations were not low (i.e. concentrations were $>0.7 \mu \mathrm{mol} / \mathrm{l}$ ). Additionally, the absence of carotenoids in serum is expected because the lipid profile of gerbils differs from that of humans in that the major circulating lipoprotein is HDL and carotenoids are predominantly associated with LDL during fasting ${ }^{(49)}$

In summary, the $9 c-, 13 c$ - and at- $\beta C$ isomers prevented retinol deficiency in gerbils when provided in amounts reflective of moderate dietary intake, and the cis- $\beta \mathrm{C}$ isomers demonstrated bioefficacies $>60 \%$ that of the at- $\beta C$ isomer when baseline liver stores were maintained. The results of these studies suggest that mild thermal processing modestly decreases the VA value of plant foods through the generation of the cis- $\beta C$ isomers. Furthermore, the currently assigned bioavailability of the cis- $\beta C$ isomers, equivalent to $50 \%$ that of the at $-\beta C$ isomer ${ }^{(4)}$, may need to be clarified as being dependent on dose size and VA status. More research is needed to elucidate the mechanism of in vivo isomerisation of $c i s-\beta C$ to at $-\beta C$ and to assess the bioavailabilities of cis- $\beta C$ isomers from plant foods in human subjects.

\section{Acknowledgements}

We thank Peter Crump, Senior Information Processing Consultant at the University of Wisconsin-Madison College of Agriculture and Life Sciences Statistical Consulting Service, for providing statistical assistance.

The present study was supported by USDA Hatch WIS01528, a College of Agricultural and Life Sciences Honors Scholarship (to K. A. B), a gift from Standard Process, Inc., and HarvestPlus. HarvestPlus (www.harvestplus.org) is a global alliance of agriculture and nutrition research institutions working to increase the micronutrient density of staple food crops through biofortification. The views expressed herein do not necessarily reflect those of HarvestPlus. The funders had no role in the design, analysis or writing of this article.

The authors' contributions are as follows: K. A. B. conducted the study; C. R. D. conducted the analyses; K. A. B. and S. A. T. analysed the data, designed the research and wrote the manuscript. All authors read and approved the final version of the paper.

Part of this work was presented at Experimental Biology Meetings in 2011 and 2013.

The authors have no conflicts of interest to declare.

\section{References}

1. Britton G, Liaaen-Jensen S \& Pfander H (2008) Carotenoids. Basel, Switzerland: Birkhäuser.

2. Grune T, Lietz G, Palou A, et al. (2010) $\beta$-Carotene is an important vitamin A source for humans. J Nutr $\mathbf{1 4 0}$, 2268S-2285S.

3. Chandler LA \& Schwartz SJ (1987) HPLC separation of cis-trans carotene isomers in fresh and processed fruits and vegetables. J Food Sci 52, 669-672.

4. Institute of Medicine (2006) Dietary Reference Intakes: The Essential Guide to Nutrient Requirements. Washington, DC: National Academies Press.

5. World Health Organization (2011) Guideline: Vitamin A Supplementation in Infants and Children 6-59 Months of Age. Geneva, Switzerland: World Health Organization.

6. Tanumihardjo SA (2008) Food-based approaches for ensuring adequate vitamin A nutrition. Compr Rev Food Sci Food Safety 7, 373-381.

7. Deming DM, Baker DH \& Erdman JW Jr (2002) The relative vitamin A value of 9-cis $\beta$-carotene is less and that of 13 -cis $\beta$-carotene may be greater than the accepted $50 \%$ that of all-trans $\beta$-carotene in gerbils. J Nutr 132, 2709-2712.

8. Lee CM, Lederman JD, Hofmann NE, et al. (1998) The Mongolian gerbil (Meriones unguiculatus) is an appropriate animal model for evaluation of the conversion of $\beta$-carotene to vitamin A. J Nutr 128, 280-286.

9. National Research Council (1995) Nutrient Requirements in Laboratory Animals, 4th ed. Washington, DC: National Academy Press.

10. Howe JA, Maziya-Dixon B \& Tanumihardjo SA (2009) Cassava with enhanced $\beta$-carotene maintains adequate vitamin A status in Mongolian gerbils (Meriones unguiculatus) despite substantial cis-isomer content. Br J Nutr 102, 342-349.

11. Levin G \& Mokady S (1995) Incorporation of all-trans- or 9-cis- $\beta$-carotene into mixed micelles in vitro. Lipids 30, $177-179$.

12. Schierle J, Hardi W, Faccin N, et al. (1995) Example 8: Geometrical isomers of $\beta, \beta$-carotene. In Carotenoids: Isolation and Analysis, vol. 1A, pp. 265-272 [G Britton, S LiaaenJensen and H Pfander, editors]. Basel, Switzerland: Birkhäuser.

13. Tanumihardjo SA \& Howe JA (2005) Twice the amount of $\alpha$-carotene isolated from carrots is as effective as $\beta$-carotene 
in maintaining the vitamin A status of Mongolian gerbils. J Nutr 135, 2622-2626.

14. Howe JA \& Tanumihardjo SA (2006) Carotenoid-biofortified maize maintains adequate vitamin A status in Mongolian gerbils. J Nutr 136, 2562-2567.

15. MacCrehan WA \& Schönberger E (1987) Reversed-phase high performance liquid chromatographic separation and electrochemical detection of retinol and its isomers. J Chromatogr 417, 65-78.

16. Davis C, Jing H, Howe JA, et al. (2008) $\beta$-Cryptoxanthin from supplements or carotenoid-enhanced maize maintains liver vitamin A in Mongolian gerbils (Meriones unguiculatus) better than or equal to $\beta$-carotene supplements. Br J Nutr 100, 786-793.

17. Green MH, Green JB \& Lewis KC (1987) Variation in the retinol utilisation rate with vitamin A status in the rat. $J$ Nutr 117, 694-703.

18. Tanumihardjo SA (2011) Vitamin A: biomarkers of nutrition for development. Am J Clin Nutr 94, 658S-665S.

19. Tang G, Qin J, Dolnikowski GG, et al. (2000) Vitamin A equivalence of $\beta$-carotene in a woman as determined by a stable isotope reference method. Eur J Nutr 39, 7-11.

20. Simon PW, Tanumihardjo SA, Clevidence BA, et al. (2008) Role of color and pigments in breeding, genetics, and nutritional improvements of carrots. In Color Quality of Fresh and Processed Foods, pp. 151-164 [CA Culver and RE Wrolstad, editors]. Washington, DC: American Chemical Society.

21. Ribaya-MercadoJD, Solon FS, Solon MA, et al. (2000) Bioconversion of plant carotenoids to vitamin A in Filipino school-age children varies inversely with vitamin A status. Am J Clin Nutr 72, 455-465.

22. Haskell MJ, Jamil KH, Hassan F, et al. (2004) Daily consumption of Indian spinach (Basella alba) or sweet potatoes has a positive effect on total-body vitamin A stores in Bangladeshi men. Am J Clin Nutr 80, 705-714.

23. Duel HJ, Johnston CH, Meserve ER, et al. (1945) Stereochemical configuration and provitamin A activity IV. Neo$\alpha$-carotene and neo- $\beta$-carotene. Arch Biochem 7, 247-255.

24. Johnson RM \& Baumann CA (1947) Storage and distribution of vitamin A in rats fed certain isomers of carotene. Arch Biochem 14, 361-367.

25. Sweeny JP \& Marsh AC (1973) Liver storage of vitamin A in rats fed carotene stereoisomers. J Nutr 103, 20-25.

26. Pollack J, Campbell JM, Potter SM, et al. (1994) Mongolian gerbils (Meriones unguiculatus) absorb $\beta$-carotene intact from a test meal. J Nutr 124, 869-873.

27. House WA, Apgar J \& Smith JC (1997) The gerbil: a model for studying the metabolism of $\beta$-carotene and minerals. Nutr Res 17, 1293-1302.

28. Ribaya-Mercado JD, Holmgren SC, Fox JG, et al. (1988) Dietary $\beta$-carotene absorption and metabolism in ferrets and rats. $J$ Nutr 119, 665-668.

29. Biesalski HK \& Weiser H (1993) $\beta$-Carotene supplements cannot meet all vitamin A requirements of vitamin Adeficient rats. NY Acad Sci 69, 216-219.

30. Grolier P, Agoudave S \& Azais-Braesco V (1995) Comparative bioavailability of diet-, oil-, and emulsion-based preparations of vitamin A and $\beta$-carotene in the rat. Nutr Res 15, 1507-1516.

31. Ferruzzi MG, Lumpkin JL, Schwartz SJ, et al. (2006) Digestive stability, micellarization, and uptake of $\beta$-carotene isomers by Caco-2 human intestinal cells. J Agric Food Chem 54, $2780-2785$

32. Thakkar SK, Maziya-Dixon B, Dixon AGO, et al. (2007) $\beta$-Carotene micellarization during in vitro digestion and uptake by $\mathrm{Caco}-2$ cells is directly proportional to $\beta$-carotene content in different genotypes of cassava. J Nutr $\mathbf{1 3 7}$ 2229-2233.

33. Aherne SA, Daly T, Jiwan MA, et al. (2010) Bioavailability of $\beta$-carotene isomers from raw and cooked carrots using an in vitro digestion model coupled with a human intestinal Caco-2 cell model. Food Res Int 43, 1449-1454.

34. Rushin WG, Catignani GL \& Schwartz SJ (1990) Determination of $\beta$-carotene and its cis isomers in serum. Clin Chem 36, 1986-1989.

35. Gaziano JM, Johnson EJ, Russell RM, et al. (1995) Discrimination in absorption or transport of $\beta$-carotene isomers after oral supplementation with either all-trans- or 9-cis$\beta$-carotene. Am J Clin Nutr 61, 1248-1252.

36. Johnson EJ, Krinsky NI \& Russell RM (1996) Serum response of all-trans and 9-cis isomers of $\beta$-carotene in humans. $J \mathrm{Am}$ Coll Nutr 15, 620-624.

37. Deming DM, Teixeria SR \& Erdman JW Jr (2002) All-trans $\beta$-carotene appears to be more bioavailable than 9-cis or 13 -cis $\beta$-carotene in gerbils given single oral doses of each isomer. J Nutr 132, 2700-2708.

38. Stahl W, Schwarz W \& Sies H (1993) Human serum concentrations of all-trans $\beta$ - and $\alpha$-carotene but not 9-cis $\beta$-carotene increase upon ingestion of a natural isomer mixture obtained from Dunaliella salina (Betatene). J Nutr 123, $847-851$

39. Stahl W, Schwarz W, von Laar J, et al. (1995) All-trans $\beta$ carotene preferentially accumulates in human chylomicrons and very low density lipoproteins compared with the 9-cis geometrical isomer. J Nutr 125, 2128-2133.

40. Ben-Amotz A \& Levy Y (1996) Bioavailability of a natural isomer mixture compared with synthetic all-trans $\beta$-carotene in human serum. Am J Clin Nutr 63, 729-734.

41. You CS, Parker RS, Goodman KJ, et al. (1996) Evidence of cis-trans isomerization of 9-cis- $\beta$-carotene during absorption in humans. Am J Clin Nutr 64, 177-183.

42. Nagao A \& Olson JA (1994) Enzymatic formation of 9-cis, 13 -cis, and all-trans retinals from isomers of $\beta$-carotene. FASEB J 8, 968-973.

43. Mills JP, Simon PW \& Tanumihardjo SA (2007) $\beta$-Carotene from red carrots maintains vitamin A status, but lycopene bioavailability is lower relative to tomato paste in Mongolian gerbils. J Nutr 137, 1395-1400.

44. Arscott SA, Howe JA, Davis CR, et al. (2010) Carotenoid profiles in provitamin A-containing fruits and vegetables affect the bioefficacy in Mongolian gerbils. Exp Biol Med 235, $839-848$

45. La Frano MR, Woodhouse LR, Burnett DJ, et al. (2012) Biofortified cassava increases $\beta$-carotene and vitamin A concentrations in the TAG-rich plasma layer of American women. Br J Nutr 110, 310-320.

46. Tanumihardjo SA, Palacios N \& Pixley KV (2010) Provitamin A carotenoid bioavailability: what really matters? Int J Vitam Nutr Res 80, 336-350.

47. Rock CL, Lovalvo JL, Emenhiser C, et al. (1998) Bioavailability of $\beta$-carotene is lower in raw than in processed carrots and spinach in women. $J$ Nutr 128, 913-916.

48. Bresnahan KA, Arscott SA, Khanna H, et al. (2012) Cooking enhances but the degree of ripeness does not affect provitamin A carotenoid bioavailability from bananas in Mongolian gerbils. J Nutr 142, 2097-2104.

49. Dosti MP, Mills JP, Simon PW, et al. (2006) Bioavailability of $\beta$-carotene $(\beta C)$ from purple carrots is the same as typical orange carrots while high- $\beta C$ carrots increase $\beta C$ stores in Mongolian gerbils (Meriones unguiculatus). Br J Nutr 96, $258-267$. 